\title{
Exploring the Effects of Personal Carbon Trading (PCT) System on Carbon Emission and Health Issues: A Preliminary Study on the Norfolk Island
}

\author{
Gary Webb \\ School of Health and Human Sciences, Southern Cross University \\ Hogbin Drive Lismore, NSW, 2482, Australia \\ Email: g.webb.23@student.scu.edu.au \\ Alex Hendry \\ Southern Cross Business School, Southern Cross University \\ Hogbin Drive Bilinga, Qld, 4225, Australia \\ Email: alex.hendry@scu.edu.au \\ Bruce Armstrong \\ Southern Cross Business School, Southern Cross University \\ Hogbin Drive Coffs Harbour, NSW, 2450, Australia \\ Email: bruce.armstrong@scu.edu.au \\ Robyn McDermott \\ School of Population Health, University of South Australia \\ Adelaide, SA, 5001, Australia \\ Email: robyn.mcdermott@unisa.edu.au \\ Boyd Swinburn \\ Population Health, Deakin University \\ 221 Burwood Highway, Burwood, 3125, Australia \\ Email: boyd.swinburn@deakin.edu.au \\ Garry Egger \\ School of Health and Human Sciences, Southern Cross University \\ Lismore, NSW, 2482, Australia \\ Email: eggergj@gmail.com
}

\begin{abstract}
The Norfolk Island Carbon and Health Evaluation (NICHE) Program is a project to trial the effects of a Personal Carbon Trading (PCT) system aimed at reducing carbon emissions and obesity related behaviours. This paper reports on a series of factor analyses designed to test attitudinal associations from a baseline survey carried out on the island. A self-completed questionnaire was offered to a randomly selected adult in each of the 800 households on Norfolk Island in the South Pacific. This was the first part of a three-tiered baseline survey of the island following the WHO STEPS approach. Items designed to measure attitudes to obesity, global warming/climate change, and the process of Personal Carbon Trading were factor analysed using Principal Axis Factoring (PAF). Correlations between the derived factors and other variables from the study were then examined. Three main
\end{abstract}


Webb et al.

factors designated 'weight consciousness', 'environmental consciousness' and 'optimism' were found to account for over $53 \%$ of the total variance in the data amongst the measures related to environmental and health consciousness. A single factor was derived from analysis of the variables included to measure attitudes to PCT that explained $56 \%$ of the total variance. Significant associations $(\mathrm{p}<0.01)$ were evident between factors derived from attitudes to body weight and attitudes to carbon emissions and global warming. Correlations amongst the factors measuring attitudes to obesity and the environment and attitude towards PCT revealed significant relationships $(\mathrm{p}<0.01)$, even before PCT had been rolled out on the Island. The associations evident between obesity and environmental degradation could help reframe current discussions around climate change and obesity management and the role PCT can play in influencing health and environmental behaviours.

Keyword: Personal Carbon Trading System, Global Warming, Obesity, Environmental Behaviours, BMI, NICHE

\section{Introduction}

The Norfolk Island Carbon and Health Evaluation (NICHE) study was established in 2011 to test the effects of a simulated Personal Carbon Trading (PCT) system on carbon emissions associated with climate change and obesity ${ }^{1}$. The rationale of the study is that there is a common causality for both apparently disparate problems as carbon emissions and weight gain, through modern human behaviours (ie. personal inactivity through the use of carbon emitting fossil-fuel powered transport; consumption of high energy-dense processed foods) $)^{2,5}$

All residents of Norfolk Island in the South Pacific ( 1800) have been offered a carbon card that allows participants to track their carbon footprint associated with non-renewable energy sources (fuel, gas and electricity generated from a diesel power station). Participants are given feedback on their carbon usage compared to national norms and a personal carbon allowance (target). The intent is to also monitor the carbon footprint associated with high energy dense, processed foods at a later date once the system is established. A household survey was conducted in March 2012 to measure baseline attitudes and behaviours for comparison with a post-intervention follow-up two years later. The current paper focuses on a series of factor analyses of survey items within the baseline study associated with attitudes to obesity, climate change and personal carbon trading. The aim was to investigate relationships between attitudes and beliefs about health and the environment, with a view to a possible re-framing of environmental issues to be more personally relevant with reference to body weight.

\section{Background to the Project}

Researching the link between obesity and an individual's carbon footprint is the primary objective of the NICHE project. This link has been proposed by a number of researchers however an extensive search of the literature has not shown any research where it has been tested. The researchers believe that the NICHE project is the first study of its kind to explore the relationship between obesity and an individual's carbon footprint.

"Compared with a normal population distribution of BMI, a population with $40 \%$ obesity requires $19 \%$ more food energy for its total energy expenditure. Greenhouse gas emissions from food production and car travel due to increases in adiposity in a population of 1 billion are estimated to be between 0.4 Giga tonnes (GT) and 1.0GT of carbon dioxide equivalents per year"18.

An increase in calorie consumption and a decrease in calorie expenditure are largely to blame for the obesity epidemic. Increased consumption of meat, meat based food products and highly processed energy dense foods in conjunction with a decrease in whole plant based foods has caused the increase in calorie consumption. Fossil fuel powered transport has been a major cause in the decrease in calorie expenditure as has increased carbon-rich production of energy dense foods 19

Meat and highly processed foods are very carbon intensive and have a large carbon foot print compared to whole plant based foods. This is due to their transport, refrigeration, packaging and manufacturing processes. Fossil fuel powered transport is also highly carbon intensive and has a large carbon foot print. These behaviours compound one another and in conjunction lead to an increase in an individual's carbon footprint and a calorie imbalance which in turn lead to obesity ${ }^{19}$. Researchers $^{20,21}$ have begun speculating that there is a link between an individual's carbon footprint, greenhouse gases, climate change and the rising obesity epidemic that started in the developed world and has now spread to developing countries as they increase in affluence $^{18}$. 
Faergeman $^{20}$ was one of the first researchers to propose this connection in his journal article "Climate change and preventive medicine" that was published in the European Journal of Cardiovascular Prevention \& Rehabilitation. Similar arguments were made in the article "Global environmental change and health: impacts, inequalities, and the health sector", ${ }^{21}$ in the British Medical Journal and in the paper "Population adiposity and climate change"18 published in the International Journal of Epidemiology. Garry Egger, one of the principal researchers in the NICHE project, proposed PCT as an option for dealing with both climate change and obesity in the article 'Personal carbon trading: a potential 'stealth' intervention for reducing obesity? ${ }^{22}$ and again in the book he coauthored with Boyd Swinburne entitled 'Planet Obesity: How we're eating ourselves and the planet to death ${ }^{19}$.

While the various schemes target different carbon emissions, they are all based around the trading and/or allocation of carbon 'credits'. All of the schemes propose using independent committees to set policies and caps related to the value and allocation of 'credits'. Individuals can buy or sell (trade) their credits as needed. All of the schemes also propose having a card or similar that would allow users to deduct credits from their allocations as they make purchases.

Political acceptability is one of the major factors delaying the implementation of PCTS. "In assessing the current state of the debate on individual carbon trading, we found a range of interests largely focused on the operational minutiae of specific schemes and on examining the minor theological differences between them. Yet the differences between the schemes appear to be less important at this stage than the largely untested assumptions shared by them all about public responses and political feasibility" 23 .

This is slowly starting to change. Since Roberts and Thumin $^{23}$ published their study there have been a growing number of studies that have looked directly or indirectly at the political acceptability ${ }^{24}, 25,26,27,28,29,30$. As with other PCT research, with a few exceptions these studies have largely focused on the UK.

\section{Norfolk Island}

Norfolk Island is an $8 \times 5 \mathrm{~km}$ volcanic island in the South Pacific approximately $1500 \mathrm{~km}$ from the east coast of Australia and 1200km from the northern tip of New Zealand. It is home to $\sim 1800$ residents, many of whom are descendants of the original Bounty mutineers relocated from Pitcairn Island in 1856, with migrants from Australia and New Zealand accounting for the remainder of the permanent population. It was chosen for a test location of the simulated PCT because of its isolation (all incomings and outgoings can be easily measured), and its relatively affluent, westernised culture and self-governance structure supportive of the current research. The study is a 3-year case study design with pre and post intervention evaluation.

\section{Sample Selection and Validation}

A baseline household survey was conducted as part of the pre-test evaluation in March 2012. Only the first part of the World Health Organisation 'STEPS' survey approach $^{6}$ used in the baseline study is reported here. The survey was a blanket survey of a randomly chosen individual from each of the $\sim 800$ households on Norfolk Island at the time of the survey. The island was split into 6 census regions to help facilitate the process. A questionnaire was developed including aspects of existing tools used to measure demographics and $\mathrm{SES}^{7,8}$, environmental behaviours ${ }^{9}$, health behaviours $^{10,11}$, attitudes towards climate change ${ }^{12}$, and personal carbon trading $^{13}$.

Questionnaires were delivered personally to households in support of six community groups incentivised to increase questionnaire completion in a census region through a small donation given based on completed questionnaires. Questionnaires were anonymous and were limited to one per household to be completed by an adult who was randomly selected based on the day of the month in which he or she was born. Once completed, participants returned questionnaires to 1 of 2 centralised drop-off locations on the island, or collected by one of two project officers on the island. Participation in the survey was voluntary and consent was implied through participation. Ethics approval was granted through Southern Cross University in January 2012 (ECN-12-012).

Of the 800 surveys delivered to all households on the island, 423 were returned. Demographic data were compared with data gathered from the Norfolk Island Census carried out on the island in $2011^{7}$. There were no statistical differences between survey and sample proportions on age, residential status, people per household, vehicles per household, those using gas cooking, solar power or having a home water tank. 
There was a slight gender difference between samples, with less males (40.2\% of total) making up the sample population than the census survey population (47.8\%).

\section{Survey Structure}

The survey items from Capstick and Lewis's ${ }^{26}$ study contributed towards the NICHE baseline survey instrument. They ran a detailed PCT computer based simulation on 65 participants for the UK Energy Research Department. Their study involved two components. The first "entails a computer-based simulation of PCA in which participants complete a simple carbon footprint calculator and then make a series of decisions in light of a personal carbon allowance allocated to them" ${ }^{26}$. The second "entails a comparative questionnaire, in which participants are asked to indicate willingness to reduce emissionsrelevant behaviors" 26 . The questions used by them in their questionnaire were used in part to develop the PCT questions in the survey that was delivered to participants in the NICHE project.

The NICHE project is multi-disciplinary involving information systems, health, environmental concerns and global warming, carbon emissions and carbon trading. The multidisciplinary nature of the study was reflected in the design and construction of the survey. It contained a range of questions covering the information systems, health, environment and the carbon emissions components of the NICHE program. Some of the questions were specifically aimed at the individual respondent while others were aimed at their household. It was constructed in sections which aligned with the researcher's expectations that there were higher order factors underlying the data.

Some of the questions used in the NICHE survey were derived in part or based on survey items from the following sources:

- Environmental behaviours - Department of Environment 2012

- Health behaviours - WHO GPAQ, Cancer Council Food Frequency

- $\quad$ Attitudes towards climate change - CSIRO 2011

- Personal carbon trading - Stuart and Capstick 2009, TAM2 surveys

- $\quad$ Demographic and socioeconomic status - Norfolk Island census 2011

- $\quad$ Anthropometrics - WHO STEP wise 2008
Additional questions were developed by the NICHE research team to cover aspects of the study for which there were no existing studies.

Questionnaire items considered in the following analyses all used 7-point Likert scales. The questionnaire items are shown in Appendices 1A, 1B and 1C. A key part of the analysis is identification of structures underlying the data to determine if there are key items that group under latent variables. Identification of these is important so they can be taken forward in the study for the post-evaluation of attitudes after the modified PCT System has been simulated on the Island for at least 12 months. Examination of potential structures underlying the data was undertaken using exploratory factor analysis (EFA). The data was examined in blocks proportionate with the survey which was constructed with distinct question blocks in mind that were based on measuring key aspects of respondents' health and understanding of environmental issues. While normal practice would dictate that all items be examined simultaneously, the number of items in the survey and the fact that it was put together with key constructs in mind make it acceptable to look at expected structures. Principal Axis Factoring (PAF) with oblimin rotation was used for factor extraction. This factor extraction technique provides good factor identification with oblimin rotations cited ${ }^{14}$ as the best technique to use where factor structures could be used in structural equation modelling (SEM). Oblique (oblimin) rotation was chosen rather than orthogonal rotation because oblique rotation has the advantage of allowing factors to be either correlated or uncorrelated.

\section{Limitations of the study and the sample}

Norfolk Island is a closed system which makes it ideal for this study. However this suitability also means that while the results of the study are comprehensive the extrapolation of results to the general population needs to be undertaken cautiously. The population of the Island is reasonably representative of other developed locations yet it needs to be recognized that the geographic and demographic characteristics can reasonably be expected to affect attitudes to climate change and health. For example, as all resources have to be shipped to the island electricity and fuel are more expensive and a larger proportion of people have solar power and solar hot water than in other developed 
locations which will ultimately affect an individual's carbon foot print.

Another limitation of the study is that the survey was administered to gather both household data and individual data. Given the survey was completed by a member of the household the attitudinal items reflect that person's views and not necessarily the views of all members of the household. However, given the number of responses and the range of characteristics, then the survey could be held to be representative of the views of the broader population of Norfolk Island.

It also needs to be recognized that this survey has been administered to gather data to develop a baseline on attitudes and household characteristics as a precursor to the roll-out of a PCTS on the Island. A second survey will be conducted 12 months after system roll-out that will aim to investigate if an understanding of personal carbon footprints influences personal behaviours in relation to health. The results being reported here are the baseline parameters that will be re-evaluated in a secondary study that will be conducted across 2014 and 2015.

\section{EFA - Health \& Environmental Consciousness}

The first EFA was run on the items shown in Appendix 1A. The appropriateness of this group of items for factor analysis was established via Bartlett's test of sphericity and the Kaiser-Meyer-Olkin (KMO) measure of sampling adequacy (MSA). This showed the data suitable for factor analysis $\left(x^{2}[78]=1116.98, \mathrm{p}<.001\right.$ and MSA $=0.80$ ). Before the analysis was run, the item B10 was eliminated from further analysis because it was not correlated with any of the other items in this group. Factor analysis carried out on the remaining 12 items measuring respondent's attitudes to obesity and the environment showed that although there were 4 factors extracted (Eigenvalues $>1.0$ ), three of these explained over $53 \%$ of the total variance (see Tables 1 and 2 ). The $4^{\text {th }}$ factor, which explained less than $9 \%$, was comprised of items that already loaded on the other 3 factors and as such the first 3 factors are the ones labelled below.
Table 1: Factor pattern demonstrating similarities in health and the environment

\begin{tabular}{|c|c|c|c|c|}
\hline Factor & 1 & 2 & 3 & 4 \\
\hline $\begin{array}{l}\text { Maintain healthy weight if I } \\
\text { wanted }\end{array}$ & .713 & & & \\
\hline Try to eat healthy food & .635 & & & .392 \\
\hline $\begin{array}{l}\text { Walking/cycling instead of car } \\
\text { reduce weight }\end{array}$ & .560 & & & -.350 \\
\hline Unlikely to be obese & .559 & & & \\
\hline Overweight serious health effects & .424 & & & \\
\hline $\begin{array}{l}\text { Obesity solved by medical } \\
\text { advances }\end{array}$ & & .640 & & \\
\hline $\begin{array}{l}\text { Technology solve environmental } \\
\text { problems }\end{array}$ & & .534 & & \\
\hline $\begin{array}{l}\text { Financial incentive reduce } \\
\text { environmental impact }\end{array}$ & & .310 & & \\
\hline $\begin{array}{l}\text { Important to have low carbon } \\
\text { footprint }\end{array}$ & & & -.786 & \\
\hline $\begin{array}{l}\text { Households can reduce } \\
\text { greenhouse emissions }\end{array}$ & & & -.681 & \\
\hline $\begin{array}{l}\text { Buy environmentally friendly } \\
\text { products }\end{array}$ & & & -.614 & .425 \\
\hline Worried about climate change & & & -.588 & \\
\hline
\end{tabular}

- $\quad$ Extraction Method: Principal Axis Factoring.

- Rotation Method: Oblimin with Kaiser Normalization.

- Rotation converged in 25 iterations.

Table 2: Total Variance Explained

\begin{tabular}{lrrr}
\hline Factor & \multicolumn{3}{c}{$\begin{array}{c}\text { Initial Eigenvalues } \\
\text { \% of }\end{array}$} \\
& Total & \multicolumn{3}{c}{ Variance } & Cumulative \% \\
\hline 1 & 3.699 & 30.822 & 30.822 \\
2 & 1.556 & 12.970 & 43.792 \\
3 & 1.207 & 10.061 & 53.853 \\
4 & 1.007 & 8.394 & 62.248 \\
5 & .868 & 7.235 & 69.483 \\
6 & .735 & 6.126 & 75.609 \\
7 & .646 & 5.380 & 80.989 \\
8 & .600 & 5.001 & 85.989 \\
9 & .498 & 4.149 & 90.138 \\
10 & .426 & 3.547 & 93.685 \\
11 & .406 & 3.383 & 97.068 \\
12 & .352 & 2.932 & 100.000 \\
\hline
\end{tabular}

Extraction Method: Principal Axis Factoring.

a. When factors are correlated, sums of squared loadings cannot be added to obtain a total variance.

Factor 1 shown in Table 1 was labelled 'Weight Consciousness' as all of the questions relate to body 
weight, some indirectly through health behaviours. Factor II 'Optimism' refers to hope for the future and that technological advances will solve both medical and environmental problems and that financial incentives could influence behaviour and factor III, 'Environmental Consciousness' relates to an individual's concerns for the environment and whether individuals can have an impact.

Table 3: Factor correlation matrix

\begin{tabular}{lrrrr}
\hline Factor & $\mathbf{2}$ & $\mathbf{3}$ & $\mathbf{4}$ & \\
\hline 1 & & .003 & $-.530^{* *}$ & -.014 \\
2 & & & -.138 & -.123 \\
3 & & & .007 \\
\hline
\end{tabular}

Extraction Method: Principal Axis Factoring.

Rotation Method: Oblimin with Kaiser Normalization.

Correlation scores between these 3 factors shown in Table 3 shows a single significant relationship ( $\mathrm{r}=0.530$; $\mathrm{p}<.01$ ) between factor 1 (Weight Consciousness) and factor 3 (Environmental Consciousness), but no relationship between these and factor 2 (Optimism). This suggests that although Optimism may be a construct worth examining further, it is not part of a higher order variable overlaying this set of items.

Items measuring attitudes to Personal Carbon Trading (PCT) are shown in Appendix 1B. Factor analysis on this set of items resulted in a single factor accounting for over $56 \%$ of the total variance, with no other factor explaining more than $10 \%$. Given the correlations among these items this was not unexpected as they all relate clearly to attitudes towards acceptability of a PCT system.

Items included in the survey to measure actions related to climate change are shown in Appendix 1C. Factor analysis resulted in a single factor, considered to be 'Environmental Action' explaining nearly $47.5 \%$ of the total variance among these items.

\section{Correlations - health attitudes, BMI, health and environmental consciousness factors}

Body Mass Index (BMI) scores, based on self-reported height and weight $(\mathrm{n}=325)$, were categorised into bands on the following
Table 4: BMI Band Descriptors ${ }^{19}$

\begin{tabular}{llrrr}
\hline BMI & Descriptor & Band & \multicolumn{1}{c}{ N } & \multicolumn{1}{c}{$\%$} \\
\hline $40+$ & morbidly obese & 6 & 4 & 1.2 \\
& (category III obese) & & & \\
$35-40$ & category II obese & 5 & 13 & 4.0 \\
$30-35$ & category 1 obese & 4 & 54 & 16.6 \\
$24-30$ & overweight & 3 & 147 & 45.2 \\
$19-24$ & ideal & 2 & 101 & 31.1 \\
$<19$ & underweight & 1 & 6 & 1.8 \\
\hline
\end{tabular}

Table 5 shows the inter-item correlations between questions relating to health (A9, A10, A12) and climate change (F23) shown in Appendix 1D and Body Mass Index (BMI) band.

These questions were singled out as individually they help to define key attributes of survey participants. It is important to capture these attributes to inform the links between health and attitude towards the environment.

Table 5: Inter-item correlations between health and climate change items and BMI Band

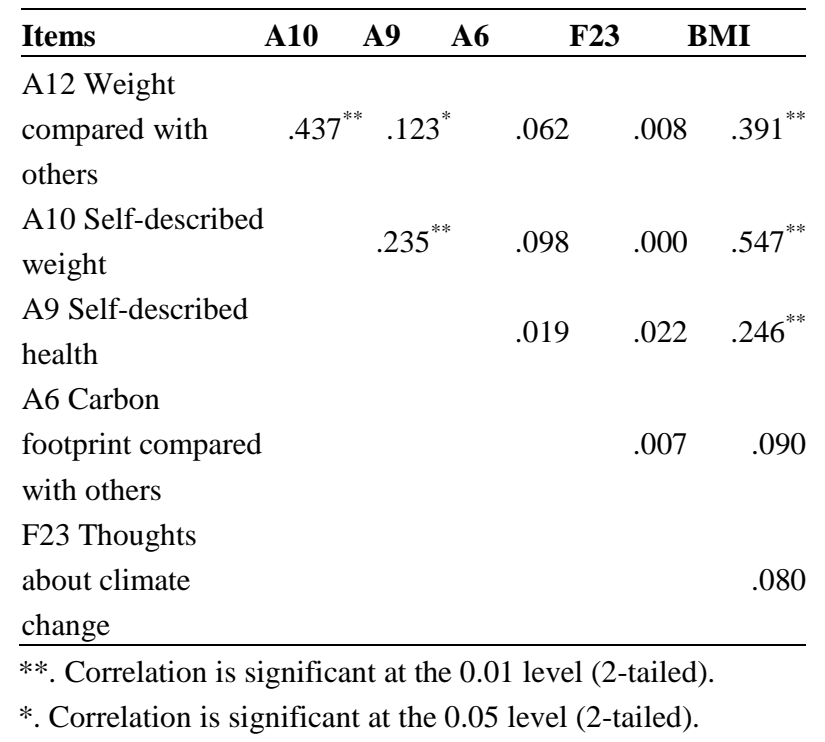

\section{Correlations - Health, Environment, BMI and PCTS}

Correlations between factors derived from the EFA are shown in

Table 
Webb et al.

Table 6: Cross Correlations between factors

\begin{tabular}{lrrrrr}
\hline Factors & 2 & $\mathbf{3}$ & $\mathbf{4}$ & $\mathbf{5}$ & BMI \\
1 Weight & & $.477^{* *}$ & $.247^{* *}$ & $.137^{* *}$ \\
consciousness & .052 & $.477^{*}$ & & \\
2 Optimism & & $.124^{*}$ & $.198^{* *}$ & .012 \\
3 Environmental & & & $.553^{* *}$ & $.206^{* *}$ \\
consciousness & & & & $.110^{*}$ \\
4 Attitudes to PCT & & & & \\
5 Environmental & & & & \\
Action' & & & & \\
\hline
\end{tabular}

**. Correlation is significant at the 0.01 level (2-tailed).

* Correlation is significant at the 0.05 level (2-tailed).

This shows significant correlations between items measuring Environmental Consciousness, Weight Consciousness, Attitudes to PCT, Environmental Action and self-reported BMI. While the relationship between Environmental Consciousness and Environmental Action is significant ( $\mathrm{p}<0.01$ ), the amount of variance $\left(\mathrm{r}^{2}<1 \%\right)$ is very small. Similarly, the relationships between Weight Consciousness and Attitudes to PCT, Weight Consciousness and Environmental Action, and Attitudes to PCT and BMI, while significant, explain only small amounts of variance. As these attitudes are targets for the NICHE program intervention, comparisons with a post-test follow-up will be pertinent.

Responses to the question about attitudes towards climate change were categorised by BMI band as shown in Figure 1. The general consensus is that climate change is happening, but there is a discrepancy between those who believe humans are causing it or that it is naturally induced. Overall 93\% of respondents believe that climate change is happening of which $32 \%$ believe it is a natural fluctuation in earth's temperatures and almost twice as many (61\%) believe humans are causing it. These attitudes are consistent across BMI bands.

\section{Correlations between the factors and demographic variables}

Correlations between the factor scores for each factor identified from the EFA and key demographic variables including gender, age and education level are shown in Table
Table 7: Correlations between Factor scores by selected demographics

\begin{tabular}{|c|c|c|c|c|}
\hline \multirow{2}{*}{$\begin{array}{r}.396^{* *} \\
.080\end{array}$} & & Age & \multicolumn{2}{|c|}{ Education } \\
\hline & $\begin{array}{l}\text { Weight } \\
\text { consciousness }\end{array}$ & .024 & .024 & .011 \\
\hline & Optimism & .043 & .003 & $.105^{*}$ \\
\hline $\begin{array}{l}.227 \\
.162^{* *}\end{array}$ & $\begin{array}{l}\text { Environmental } \\
\text { consciousness }\end{array}$ & $.163^{* *}$ & .047 & .043 \\
\hline & Attitudes to PCT & $.231^{* *}$ & $.128^{*}$ & .009 \\
\hline-.026 & $\begin{array}{l}\text { Environmental } \\
\text { activism }\end{array}$ & $.100^{*}$ & .040 & .059 \\
\hline & $\begin{array}{l}\text { F23 - Belief in } \\
\text { climate change }\end{array}$ & $.141^{* *}$ & $.142^{* *}$ & .062 \\
\hline
\end{tabular}

**. Correlation is significant at the 0.01 level (2-tailed).

*. Correlation is significant at the 0.05 level (2-tailed).

It is of interest that there were no significant correlations between Weight Consciousness, Optimism, and Age or Gender on Norfolk Island. It is not clear if this is the case in the broader population or differs between countries however there is some literature that highlights young women as being significantly more weight conscious than males ${ }^{15,16}$. Being factor scores, the correlations indicate a significant relationship exists between these variables, but does not give any indication of the nature of the relationship. In exploring this further, mean scores were calculated from the variables that made up each factor. For each of the significant relationships evident in Table 6, the distribution of the group means were examined based on gender, age band and highest education level achieved.

The analysis is based on calculations above and below the scale mid-point to indicate agreement or disagreement with the questions that comprise each factor. The analysis shows that a higher percentage of females $(84.5 \%, \underline{\mathrm{n}}=238)$ on Norfolk Island are environmentally conscious than males $(77.2 \%, \underline{n}=162)$. As well, a greater percentage of females (67.1\%) were positive towards the benefits of PCT than males (54.0\%). A greater percentage of females thought climate change was real and happening (females $95.4 \%$, males $90.1 \%$ ) and also that humans were causing it (females 66.5\%, males 53.7\%). This finding is consistent with other Australian studies that have demonstrated that females are more likely to believe in climate change and that humans are responsible ${ }^{17}$. It is interesting to note however that on Norfolk Island a greater percentage of males (48.5\%) were more likely to 
engage in environmentally friendly activities compared to females (32.5\%).

In relation to Attitudes to PCT, those over 60 years were least likely to believe that there are benefits from PCT (54.8\% 'agree'), compared with those in the 30 to 39 year age group $(76.9 \%)$.

The large majority of the surveyed population on Norfolk Island believe that climate change is happening (93.12\%, n=407). This belief was relatively consistent among all age bands with those aged $<30,30-39$, 40-49, 50-59, >59 reporting their positive beliefs towards climate change as $91.6 \%, 96.1 \%, 93.2 \%, 95.2 \%$ and $90.6 \%$ respectively. This finding is consistent with the Australian CSIRO baseline survey that uses the same question wording and response format which found that $90.6 \%$ of the broader Australians population believe that climate change is happening either through natural fluctuations in earth temperatures or human intervention $^{12}$.

Those aged $<30$ have the strongest belief that climate change is happening due to human causes (83.3\%). This belief gradually declines in each age band to $51.6 \%$ in those aged $>59$ with a greater number of participants reporting that climate change is happening due to natural fluctuations in earth temperatures as participant's age (8.3\% of those aged $<30$ progressing to $39.0 \%$ of those aged $>59$ ). This finding is somewhat consistent with the ARCCANSI survey which found that those aged over 55 have a greater tendency to believe that climate change was a result of natural causes ${ }^{17}$.

\section{Conclusions}

Key structures identified in the baseline survey provide an understanding of attitudes to a PCT system and relate these to other beliefs and variables. They also show links between attitudes towards personal health and environmental issues. These structures are key to the evaluation stage of the research where the linkages between an individual's personal carbon footprint and obesity will be examined after having experience with a PCT system. While data analyses from the studies used to develop the survey have shown structures underlying their individual data sets, to our knowledge, there has not been any study identified that has been able to develop structures that allow relationships between an individual's health and climate change attitudes to be explored. As well, there have been no data linking this information or these constructs to attitudes towards PCT systems.

The five factorial constructs identified from analysis of the data are:

- Weight consciousness

- Environmental consciousness

- Optimism

- Attitudes to PCTs

- Environmental actions

The main findings from the data analysed to date are that there are significant relationships between body weight consciousness and environment consciousness. Attitudes to behaviours associated with the type of processes instituted in a Personal Carbon Trading system also show significant relationships with both weight consciousness and environmental consciousness, possibly because both weight and environmental consciousness factors also correlated with climate change beliefs, as measured in question F23. Both factors appear to be related to behaviours associated with environmental action.

The findings provide strong support for a 'reframing' of current public discourse around climate change and personal health (specifically obesity). The apparent association of beliefs give support to the notion of emphasising the personal aspects of behaviours linked with both obesity and climate change, instead of focusing purely on environmental factors. Emphasising the health aspects of a Personal Carbon Trading (PCT) system may also more positively influence attitudes towards this type of approach to dealing with environmental issues than a focus purely on the environment. Health and the environment are, and should be promoted as being closely linked.

The findings reported in this paper are based on a survey administered to collect baseline data. The analysis shows that there are relationships between attitudes to the environment and carbon trading systems and health related indicators. Given that these are baseline data, the relationships amongst these variables will be examined in the next phase of the project after participants have experienced the simulated PCT system being rolled out on the Island.

The NICHE study is designed to examine public attitudes and political acceptability of a PCT system for modifying environmental and health related behaviours. The indications from baseline data presented here, even before the experience of such a system, is positive, but suggests the need for a possible shift in emphasis to the 
personal health advantages of such a system, to compliment the environmental gains.

\section{References}

1. The Norfolk Island Carbon and Health Evaluation (NICHE) program. [www.niche.nlk.nf]

2. Egger G: Dousing our inflammatory environment(s): is personal carbon trading an option for reducing obesity and climate change? Obesity Reviews 2008, 9(5):456-463.

3. Roberts I: How the obesity epidemic is aggravating global warming. New Scientist 2007, 2610(21).

4. Faergeman O: Climate change and preventive medicine. European Journal of Cardiovascular Prevention \& Rehabilitation 2007, 14(6):726-729.

5. Stott R: Healthy response to climate change. British Medical Journal 2006, 332(7554):1385-1387.

6. WHO STEPwise approach to chronic disease risk factor surveillance. [http://www.who.int/chp/steps/riskfactor/en/index.ht $\underline{\mathrm{ml}}]$

7. Administration of Norfolk Island: Norfolk Island: Census of Population and Housing, Census Description, Analysis and Basic Tables. In.; 2011.

8. WHO STEPwise approach to chronic disease risk factor surveillance - $\quad$ Instrument v2.1. [www.who.int/chp/steps]

9. State of NSW and the Department of Environment CCaWN: Who cares about the Environment in 2009? A survey of NSW people's environmental knowledge, attitudes and behaviours. In.; 2010.

10. Armstrong T, Bull F: Development of the World Health Organization Global Physical Activity Questionnaire (GPAQ). Journal of Public Health 2006, 14:66-70.

11. Dietary Questionnaire for Epidemiological Studies (DQES v2) User Information Guide 2009 [http://www.cancervic.org.au/dqes]

12. Leviston Z, Walker IA: Baseline Survey of Australian Attitudes to Climate Change: Preliminary Report. In.: National Research Flagships Climate Adaptation. CSIRO Ecosystem Sciences Perth; 2011.

13. Capstick S, Lewis A: Personal Carbon Allowances: A Pilot Simulation and Questionnaire. In.: UK Energy Research Centre - Demand Reduction Theme.
Environmental Change Institute, University of Oxford; 2009.

14. Gorsuch R: Factor analysis Hillsdale, NJ: L. Erlbaum Associates; 1983.

15. Mercurio A, Rima B: Watching My Weight: SelfWeighing, Body Surveillance, and Body Dissatisfaction. Sex Roles 2011, 65(1-2):47-55.

16. Paxton SJ, Wertheim EH, Gibbons K, Szmukler GI, Hillier L, Petrovich JL: Body image satisfaction, dieting beliefs, and weight loss behaviors in adolescent girls and boys. Journal of youth and adolescence 1991, 20(3):361379.

17. Leviston Z, Leitch A, Greenhill M, Leonard R, Walker I: Australians' views of climate change. In. CSIRO Report. Canberra.; 2011.

18. Edwards, P., \& Roberts, I. (2009). Population adiposity and climate change. International Journal of Epidemiology, 38(4), 1137-1140.

19. Egger, G., \& Swinburn, B. (2011). Planet Obesity: How we're eating ourselves and the planet to death: Allen and Unwin.

20. Faergeman, O. (2007). Climate change and preventive medicine. European Journal of Cardiovascular Prevention \& Rehabilitation, 14(6), 726-729.

21. McMichael, A., Friel, S., Nyong, A., \& Corvalan, C. (2008). Global environmental change and health: impacts, inequalities, and the health sector. BMJ: British Medical Journal, 336(7637), 191.

22. Egger, G. (2007). Personal carbon trading: a potential" stealth intervention" for obesity reduction? Medical Journal of Australia, 187(3), 185.

23. Roberts, S., \& Thumim, J. (2006). A rough guide to individual carbon trading. The ideas, the issues and the next steps, Centre for Sustainable Energy, UK.

24. Bird, J., Jones, N., \& Lockwood, M. (2008). Political acceptability of personal carbon trading: Findings from primary research. London, IPPR.

25. Bristow, A. L., Wardman, M., Zanni, A. M., \& Chintakayala, P. K. (2010). Public acceptability of personal carbon trading and carbon tax. Ecological Economics, 69(9), 1824-1837.

26. Capstick, S., \& Lewis, A. (2009). Personal carbon allowances: a pilot simulation and questionnaire. UK Energy Research Centre, London. 
27. Jagers, S. C., Löfgren, Å., \& Stripple, J. (2009). Attitudes to Personal Carbon Allowances: The effect of trust in politicians, perceived fairness and ideology. rapport nr.: Working Papers in Economics 360.

28. Keay-Bright, S., Fawcett, T., Howell, R., \& Parag, Y. (2008). Personal Carbon Trading (PCT): Bringing together the research community. Paper presented at the Workshop Report.

29. Parag, Y., \& Eyre, N. (2010). Barriers to personal carbon trading in the policy arena. Climate Policy, 10(4), 353-368.

30. Wallace, A. A. (2009). Reducing carbon emissions by households: the effects of footprinting and personal allowances. Institute of Energy and Sustainable Development, De Montfort University, Leicester.

\section{Appendix A.}

(A) - Health and environment questions

Data recorded using 7 Point Likert Scale - Strongly Agree (1), Neutral (4), Strongly Disagree (7)

B1 I buy environmentally friendly products as much as I can.

B2. Technology will solve future environmental problems

B3. Being overweight can have serious health effects

B4. Obesity will be solved in the future by medical advances

B5. It is important for me to have a low carbon footprint

B6. A financial incentive would encourage me to reduce my environmental impact

B7. Collectively, households can reduce the impacts of greenhouse gas emissions

B8. I always try to eat healthy food

B9. I am confident I could maintain a healthy body weight if I wanted to

B10. I would consider purchasing an electric car or bike if the price was right

B11. Walking or cycling instead of using the car can help reduce a person's weight

B12. I am unlikely to ever be obese

B13. I am worried about climate change

(B) Items relating to Personal Carbon Trading

Data recorded using 7 Point Likert Scale - Strongly Agree (1),

Neutral (4), Strongly Disagree (7)

E1. Being able to measure my carbon footprint is important to me

E2. Most people would accept a PCT system as a tool for improving the environment
E3. A PCT system would encourage me to reduce my carbon footprint

E4. A PCT system would encourage me to walk or cycle more and drive less

E5. People who reduce their carbon footprint should be rewarded in some way

E6. People with a greater carbon footprint should have to pay for it in some way

E7. A PCT system would encourage me to eat more healthy, locally grown produce

E8. A PCT system would be useful for me to help monitor my environmental impact

E9. Comparing my carbon usage to the average would influence my consumption habits

E10. There is a strong link between a person's carbon footprint and their health

(C) Items relating to environmental action

Data recorded using 7 Point Likert Scale - Never (1), Sometimes (4), Always (7)

B14. I turn the tap off when cleaning my teeth

B15. I turn lights off when not in use

B16. I sort my rubbish

B17. I look to buy second hand over brand new

B18. I consciously try to reduce waste and recycle

B19. I buy local produce, even if imported is cheaper

(D) Items relating to Health, Body Weight and Attitudes towards Climate change

A9. Do you generally consider your health to be

Poor

Fair

Good

Very good

Excellent

A10. How would you best describe yourself?

Very underweight

A bit underweight

Healthy weight

A bit overweight

Very overweight

A12. Compared to others on the island of similar age and gender do you consider your body weight to be.....

Well below average 
Webb et al.

Below average

About average

Above average

Well above average

F23. What best describes your thoughts about climate change?

I don't think climate change is happening

I have no idea whether climate change is happening or not

I think climate change is happening but it's a natural fluctuation in earth temperatures

I think climate change is happening and I think humans are largely causing it 